\title{
Linguistic Education and Economics: Way to Synergy
}

\author{
Natalia Zolotareva \\ Ural State University of Economics, Ekaterinburg, Russia
}

\begin{abstract}
The article is devoted to the problem of integrating linguistic studies into education for potential economists. This article aims to mark some important problematical items necessary to realize the reformation of higher philological education and to formulate a number of key statements that could help in future.it deals with the problem of understanding interdisciplinary as a popular important direction in higher education in universities of Russia.
\end{abstract}

\section{Introduction}

More and more specialists in higher education are currently talking about the need to introduce linguistic disciplines in the curriculum of economics universities. Interdisciplinarity was claimed about fifty years ago. Despite this fact, academic disciplines still have not switched to the new mode of teaching, they still work as churches, still adhere to traditional theoretical frameworks, research models, and methodology tools. Those who do not support the idea of introducing linguistics learning in teaching future economists can be critical and may concentrate rather on the disadvantages of the new idea. The reason seems to be as follows: the approach or the idea itself might have been adopted not adequately enough.

Economists give more attention to figures and statistical data while linguists in their view rely mainly on some messy data and their own interpretation of the facts. Mention should be made that the situation is not always like this. Currently more and more economists realise that they can and even need to communicate and collaborate efficiently in spite of the differences in the ways they invoked notions from each other's subject.

The reasons for linguists to need economics can be scientific and even political: linguists see that they should sometimes reconsider their own disciplinary traditions concerning the relevance of a language to the welfare of its speaker in such spheres as social economics and politics.

Besides, a language is not the only research domain of a linguist, a linguist is also interested in cross-cultural communication issues, which is also very vivid in economic discussions. An improved cross-disciplinary dialogue can become very productive and help both linguists and economists reach synergy: now when interdisciplinary approach is really prized, it will help economists and linguists to educate each other on matters that include both language and economic development, economic practice and language vitality, etc.

The success of an economist in political decision-making highly depends on what language they speak. They should use the language the police-makers understand and give 
the evidence they believe in. according to Grin, the language of economics as a sphere of research plays a vital role in education and "an increasingly important one in practice".

Equally, a sustained conversation with economists may help linguists reassess some of their ideological views concerning language vitality. By teaching each other, linguists and economists are sure to provide more informative and more successful assessments of the relationship betweenlanguage and economy. A cross-disciplinary bridge between linguistics and economics will assist to better understand the socioeconomic world where speakers evolve.

The term language economics was introduced by J.Marschak in 1965 meaning the economics approach to language [10]. Later it was proved by the fact that the cost-andbenefit approach to language helped during international takeovers and acquisitions. In the context of foreign trade, Carr explains that the English language has become the accepted lingua franca, like the dollar, "the currency of currencies" and proves that sharing the same language is sure to reduce the transaction costs due to the correct communication. Both language and money are considered as elements of wealth.

The ideological differences show radically different ways of language conceptualisation: for an economist it is only a tool, something practical, and linguists see it as something complex, it is associated with some ideology. In sociologically-oriented linguistics, social relations mist be taken into account, as well as social norms and expectations.

An individual's investment in university education depends greatly on whether they want to get socioeconomic success, which leads to the approach to language as a capital (and this means not only knowing a foreign language but also using the native language properly). The role of literacy with the rate of literacy as an index of economic prosperity and social advancement was for a long time criticized. Fortunately, at present it is considered that literacy and educational background have a great impact on an individual's business success [2]

Economists correlation between linguistic skills and employment looks at language as the problem and the solution to the economic integration of migrants. Without really fluent knowledge of the language and without investing into its learning a person is not able to obtain the job he or she could be qualified for.it is even considered that such a case reflects the lack of effort or willingness to work within the socioeconomic system of the country.

Economists currently tend to look at language as a human capital, which is considered as a great shift in their understanding of linguistics. Now language is already an asset people, companies and governments invest in. It is a factor which is taken into account when developing some policies. It is now looked at liked this: is it necessary to promote a particular language rather than others? What are the expenses to provide this policy? Both native and inherited languages are considered as capitals, a person's native language is looked at as indexing the ethnical identity unlike foreign languages, the learning of which is a matter of technical competence.

Economists calculate the expenses of developing such a competence in relation to education, although a foreign language can be acquired naturally if you live in a foreign country and try to interact with its native speakers.

More than that, a speaker can have more than one native language.

For Keynes, a good economist be "as aloof and incorruptible as an artist, yet sometimes as near the earth as a politician." [3] So the key to being a good economist is to combine and blend, to synthesize. So blending of skills is one of the core elements to succeed in business and economy. This is why not only economics matters but also linguistic learning is important.

Keynes gives the following advice to potential economists.

Look at history and be rigorous. Be pure but ready to transact and to communicate. 
Skills are also required from you. A good graduate program should give that. A wider vision of the world that comes over time should help. Paul Krugman, a good example of a good economist and whose defunct economist is Keynes, thinks that a good economist needs to read and listen. Krugman expands when he explains his four rules for research:

1. Listen to the Gentiles because an economist might get the metaphor wrong, but someone from a different discipline/perspective might have gotten it right;

2. Question the question, or ask not what your model can do for you, but what you can answer with your questions;

3. Dare to be silly and embrace different assumptions and like Dr. Livingston be thankful that you are there to welcome them; and

4. Simplify, simplify and be a minimalist

To all this Krugman adds the need to engage in policy relevant work because "some of my favorite papers have grown out of this policy-oriented work".

In other words, be relevant and be engaged. But Krugman would not want to go too far this route as "pretty soon you'll probably start using "impact" as a verb.

So we have a pretty good list: synthesize, develop your skills and use them, listen, question, be flexible, simplify, be relevant and engaged.

Some more can be added [8]:

1. Curiosity to challenge your models and if new data comes in, change them.

2. Honesty and personal ethics. Even nations can fail when honesty is unconstitutional.

3. Humility. After the worse crisis since the great depression, very few economists own up to the fact that even fewer predicted it and some even say that the failure to predict the crisis is because economic theory says they are unpredictable under the "efficient market hypothesis". At the risk of sounding wooly, the capacity to understand failure and adapt seems more important than ever.

4. More than a big push, in the last decade economics got a nudge and is moving from ideology economics to economics based on facts. Let the data do the talking, and debunk established truths in topics that range from the war on drugs to political correctness.

5. Humor is always good, particularly if you use it to not make a point.

6. So in that vein, it's good to have a smart partner. Nowadays most papers are written by more than 2 authors, so it probably helps if one of those authors is your partner who understands the difference between input and output when changing diapers.

All these cannot be achieved without good linguistic education blended with economic education.

The situation in higher philological education, despite the vivid problems, doesn't attract such wide public attention, as for example teaching the Russian language and literature at school. The goals of school program and a list of required reading for over two years have been the subject of active discussion in the professional environment and in special commissions of the government. However, to solve the problems without introducing changes in higher education in the sphere of philology seems impossible [1], [4], [5], [6].

Transformation to the two-level (bachelor + master) system of education is sure to provide opportunities for universities, to develop their own educational standards in the relevant disciplines and educational programs, taking into account such factors as: specificity of the region, the level of students, the material base of the University, etc.

However, the problem of standardization of curricula increased with establishing Federal educational standards pointed out some statements of the system of higher philological education. 
Establishing the bachelor degree as the initial stage of higher education resulted in eliminating additional special disciplines, it also caused a tendency towards the unification of the curricula, which in some cases looks impossible and even absurd [6].

The first three years of a bachelor degree of higher education should provide students with a lot of disciplines - humanitarian, social, economic and professional. This is necessary due to some changes in the initial input level of the first year students: the school does not provide them with basic humanitarian level, that is why modern universities are forced to compensate for this [9], [13].

It might be important to correlate the principles and forms of presentation in different lecture courses, coordinate the courses in a module and form a single concept that will allow to see the evolution of culture. For these purposes it is important to hold regular methodological workshops in which teachers represent their vision for the courses, identify existing problems of teaching[1], [14]. Coordination of different courses in the system of higher education should be based on the integrative principle: it is necessary to create courses combining linguistic and literary approaches to the different phenomena, for example, the unity between language and mind, the specificity of ethnic, gender, pictures of the world [14].

\section{Conclusions}

In Ural State University of Economics students studying World Economics and International Management have an opportunity to get a diploma of an interpreter in the sphere of professional communication. They start with introduction into General Linguistics where they learn different classifications of languages, they learn all the layers language and relations among them/ afterwards, they have the Theory of Translation, Lexicology, Stylistics of English and Russian and finally a course in Practical translation. It is a really good opportunity for them to combine their knowledge of economics and management with linguistics knowledge. Even if not each of them woks as a translator or interpreter in the future, they are sure to have a competitive advantage and a unique selling proposition as specialists in the market of Russia or any English-speaking company that deals with Russian trade.

\section{References}

1. L.Bushkanets, N. Machinina, L. Nasrutdinova, M. Sidorova, The Formation of higher philological education in Kazan University in the XIX-XXI centuries. Philology and culture, 4, 266 (2015)

2. Grin, Francois. 50 years of economics in language policy: Critical assessment and Priorities. The Economics in Language Policy, ed.by Michelle Gazzola and BerndtArne Wickstrom, Cambridge, MA: MIT Press. 21 (2016)

3. John Maynard Keyenes. The General Theory of Employment (1937)

4. I. Kim, Why does society need philologists? Accreditation in education URL: http://www.akvobr.ru/filologicheskoe_obrazovanie_perspektivy.html. Checked 25.11.2015/ (2015)

5. E.Kovtun, Why is it necessary to be a philologist today? Attractiveness of philological education in Russia. Bulletin of the Philology Council of the Association for classical University education, 10. 30 (2007)

6. E. Kovtun, Philology master's degree in Russia: yesterday and tomorrow. Bulletin of the Philology Council of the Association for classical University education, 12. 14 (2010) 
7. E. Kovtun, Guidelines for the development of the University's basic educational programs on the basis of the Federal Standards in higher professional Philology education [Electronic resource] URL: http://goosvo.ru/uploadfiles/mo/20120404084538.pdf. Checked 25.11.2015. (2015)

8. Paul. Krugman, International Economics: Theory and Policy, with Maurice Obstfeld. $7^{\text {th }}$ Edition. (2006).

9. Kuzennaya, T. The Direction of fundamentalization of higher philological education. Vestn. Baltiysk. fed. Univ,4. 66 (2007)

10. Jacob Marschak, Economics of Language. Behaviorial Science 10. 135 (1965)

11. H. Ozen, Determining the Factors of Social Phobia Levels of University Students: A Logistic Regression Analysis. Educational Process: International Journal, 5(1). 38 (2016)

12. M. Savci, F. Aysan, Relationship between Impulsivity, Social Media Usage and Loneliness. Educational Process: International Journal, 5(2). 106 (2016)

13. M. Schelkunov, M. Nikolaev, Education in the twenty-first century: facing the new challenges. Kazan, 156 (2010)

14. Cecile B. Vigouroux, Salikoko S. Mufwene, Bridging Linguistics and Economics. Cambridge University Press, (2020)

15. E. Yellina, E. Kovtun, E. Rodionova, Competences and learning outcomings: the logic presentation in educational programs Higher education in Russia, 1, 10 (2015) 